OPEN ACCESS

Edited by:

Arun K. Bhunia,

Purdue University, United States

Reviewed by:

lan Jenson,

Meat \& Livestock Australia, Australia

Tian Ding,

Zhejiang University, China

*Correspondence:

Charalampos Avraam

cavraam1@jhu.edu

Specialty section

This article was submitted to

Agro-Food Safety,

a section of the journal

Frontiers in Sustainable Food Systems

Received: 06 January 2021

Accepted: 25 February 2021

Published: 24 March 2021

Citation:

Avraam C, Lambrou AS, Jiang W and

Siddiqui S (2021) Antimicrobial

Resistance and Livestock Trade for Low and Middle Income Countries:

Regional Analysis of Global

Coordination Policies.

Front. Sustain. Food Syst. 5:650315.

doi: 10.3389/fsufs.2021.650315

\section{Antimicrobial Resistance and Livestock Trade for Low and Middle Income Countries: Regional Analysis of Global Coordination Policies}

\author{
Charalampos Avraam ${ }^{1 *}$, Anastasia S. Lambrou ${ }^{2}$, Wei Jiang ${ }^{1}$ and Sauleh Siddiqui ${ }^{3}$ \\ ${ }^{1}$ Department of Civil and Systems Engineering, Johns Hopkins University, Baltimore, MD, United States, ${ }^{2}$ Department of \\ International Health, Bloomberg School of Public Health, Johns Hopkins University, Baltimore, MD, United States, \\ ${ }^{3}$ Department of Environmental Science, American University, Washington, DC, United States
}

Antimicrobial resistance is a threat to global health, aggravated by the use of antimicrobials in livestock production. Mitigating the growing economic costs related to antimicrobial use in livestock production requires strong global coordination, and to that end policy makers can leverage global and national food animal trade policies, such as bans and user fees. Evaluation of such policies requires representing the interactions between competing producers in the global meat market, which is usually out of the scope of statistical models. For that, we developed a game-theoretic food system model of global livestock production and trade between 18 countries and aggregate world regions. The model comprises the largest producing and consuming countries, the explicit interconnections between countries, and the use of antimicrobials in food animal production. Our model allows us to provide policy insights beyond standard literature and assess the trade-off between trade, cost of a policy, and antimicrobials-induced productivity. We studied three scenarios: global increased user fees on antimicrobials, a global ban of meat imports from Brazil, and a decrease in China's meat consumption. We found that a user fee that increases the price of antimicrobials by $50 \%$ globally leads to a 33\% reduction in global antimicrobial use. However, participation of developing and emerging countries in the coordination scheme is jeopardized, since they become less competitive for meat sales compared to developed countries. When meat imports from Brazil are banned globally, importers of Brazil's meat would turn primarily to the U.S. to supplement their demand. Lastly, meeting China's medium-term lower meat consumption target would not affect global antimicrobial use, but could increase China's antimicrobial use by $11 \%$. We highlighted the importance of trade for the outcome of a policy and concluded that global cooperation is required to align the incentives of all countries toward tackling antimicrobial resistance.

Keywords: antimicrobial resistance, LMIC, trade, equilibrium model, livestock, global coordination, policy assessment 


\section{INTRODUCTION}

Antimicrobial resistance (AMR) is a threat to global health, accounting for over 700,000 deaths each year (O'Neill, 2014). When a microbial pathogen becomes resistant, antimicrobials are no longer effective against the pathogen. Therefore, the treatment options for a patient who is infected by a resistant microbial pathogen are either unavailable or would require healthcare providers to use less effective treatment methods. Moreover, infection by a resistant microbial pathogen can complicate the recovery of vulnerable patients from complex surgeries (CDC, 2013). This disease burden is predicted to contribute toward 10 million global deaths by 2050 (O'Neill, 2014). AMR and subsequent infection in individuals can result from multiple pathways, such as antimicrobial use in the human sector as well as the animal sector. The importance of certain antimicrobials for human medicine, categorized under "critically important" antimicrobials, prompted the World Health Organization (WHO) to advise countries to restrict their use in the food animal sector (WHO, 2011). The suggestion is based also on the observation that restriction of antimicrobials for veterinary purposes reduces antimicrobial resistance (WHO, 2002). Antimicrobials are used in livestock husbandry also for disease treatment, prophylaxis (Landers et al., 2012), and for growth promotion (Wegener et al., 1999). Global procurement of antimicrobials in the animal sector related to livestock production is estimated to be $73-100 \%$ higher than the purchases for the human health sector (Van Boeckel et al., 2017). Excessive antimicrobial use could reflect unsanitary breeding conditions (Martin et al., 2015) or the use of antimicrobials as a means to increase global livestock production to meet consumer demand.

The use of antimicrobials in animals can lead to AMR in humans through direct and indirect transmission mechanisms, such as exposure to livestock infected with AMR pathogens or through contaminated retail meat (Woolhouse et al., 2015). Many lower and middle income countries (LMICs), such as China, India, and Brazil, are exhibiting drastic increase in their demand and production of livestock for retail meat (Tilman et al., 2011). In tandem, the impacts of the growing AMR burden are also disproportionately felt by LMICs (Van Boeckel et al., 2019).

The inclusion of AMR under Goal 3 of the U.N. Sustainable Development Goals (SDGs), which aim to "ensure healthy lives and promote well-being for all at all ages" (ECOSOC, 2019), highlights the growing interest of the global community to tackle AMR. Tackling AMR in LMICs is related to at least two Goal 3 targets. Target 3.8. aims to "ensure universal health coverage...for all," while target 3.B. focuses on the "development of vaccines and medicines for the communicable and noncommunicable diseases that primarily affect developing countries" (ECOSOC, 2015). Strong global coordination is needed to monitor and regulate the use of antimicrobials in livestock production to mitigate AMR (Rogers Van Katwyk et al., 2016). Policies can serve as critical tools to initiate coordination efforts and promulgate changes in global norms to support human and animal health.

Given inter-country geopolitical relationships, global livestock trade policies can prove valuable in reducing regional antimicrobial use. Global and national food animal trade policies can mitigate growing AMR burdens by employing mechanisms, such as bans, user fees, and restrictions on products raised using antimicrobials. Trade restrictions in particular represent a key policy lever that can reinforce global coordination and commitment to the global reduction of antimicrobial use. Given that country-specific policies can disproportionately diminish the productivity of one country compared to another, the WHO argues for the need of a global coordination scheme that would ensure the alignment of global incentives (WHO, 2015).

Computational tools can support the design and assessment of global policies targeting antimicrobial use in the livestock sector. Novel food systems models need to account for the competing objectives of different trade participants, incorporate the use of antimicrobials, and endogenously account for explicit inter-country trade changes (Hanefeld et al., 2017; George, 2018) that will result from global and national AMR policies. Incorporating all three features in a single framework calls for a new modeling paradigm. We categorize the existing models which are used to asses global policies related to antimicrobial use into two broad categories. The first category includes standard partial equilibrium models of the food sector that represent the interactions between a range of agricultural products and are rich in spatial detail, but do not incorporate either the use of antimicrobials in livestock production or the explicit trade links (OECD-FAO, 2015). The second category includes statistical models with detail on the variety of antimicrobials used in animal husbandry. These models do not properly account for the economic and trade interactions between different agents (Van Boeckel et al., 2017).

We identified and assessed potential strategies for governments in LMICs that could reduce the use of antimicrobials in food animal production. We developed a game-theoretic model of global livestock production and trade between 18 countries and aggregate world regions, comprising the largest producing and consuming countries. In our model, each market participant, country-level producer or inter-regional transporter, aims to maximize their individual profit. When considering the economic incentive behind antimicrobial use in livestock production, a game-theoretic model is more suitable compared to a statistical model for the assessment of policy interventions. We also model the explicit interconnections between countries and the use of antimicrobials in food animal production. We used our model to assess the impact of three different global livestock policies: one scenario driven by a global shift in antimicrobial policy and two scenarios from the trade perspective of Brazil and China. Our analysis revealed potential conflicts of interest between international policy participants and allowed us to provide suggestions to better design similar policy mechanisms to support global health. 


\section{METHODS}

\subsection{Integrated Global Antimicrobial Use and Livestock Trade Model (IGAULTM) Description}

For the purpose of this study, we developed the Integrated Global Antimicrobial Use and Livestock Trade Model (IGAULTM). IGAULTM is a game-theoretic equilibrium model that simulates global livestock production, consumption, and trade between countries and world regions. The model distinguishes between three categories of food animal products: poultry, pork, and beef. Compared to other livestock production models, IGAULTM also incorporates antimicrobial use in livestock production, and country-to-country trade in an integrated framework.

The focus on global policies and trade requires consistent production, consumption, and trade data for all countries and regions included in this study. The availability of data from the Food and Agriculture Organization Corporate Statistical Database (FAOSTAT) (FAOSTAT, 2020) led us to model production, consumption, and trade of livestock at the country level. IGAULTM comprises 15 countries and three aggregate geographical regions that include countries not explicitly represented. IGAULTM countries include all major producers and consumers of pork, beef, and poultry, such as the European Union member countries (EU) except for the Republic of Cyprus, ${ }^{1}$ the United Kingdom, USA, Russia, China, India, and Brazil, which accounted for $55 \%$ of global meat production in 2015. The model also includes major livestock importers, such as the Netherlands, Japan, and the Republic of Korea. Table 1 lists all countries considered in the model, either as standalone countries or as parts of a region. Given our focus on the impact of trade, the aggregation of regions for the Rest Of Europe (ROE) and the Rest Of America (ROA) is based on geographic proximity. Finally, the Rest Of World (ROW) region includes all remaining countries for which antimicrobial use data were available. The model runs from 2015 through 2028 with annual time steps.

\subsection{Market Agents Representation in IGAULTM}

In our framework, production and consumption in each region is decided by an aggregate representative producer and an aggregate representative consumer. A complete listing of model sets, parameters, and variables is provided in Table 2. IGAULTM is a game-theoretic model, meaning that every aggregate representative agent optimizes their own objective. Specifically, in the absence of antimicrobials, the representative producer of livestock product $l p$ in region $r$ would decide how much to produce in year $t$ by maximizing their inter-temporal profit which comprises total revenues [first term in (1)] minus total cost [second term in (1)], i.e.,

\footnotetext{
${ }^{1}$ Data on livestock production (FAOSTAT, 2020) and the use of antimicrobials in the livestock sector (Van Boeckel et al., 2015) were not available for the Republic of Cyprus in the respective databases.
}

TABLE 1 | Regional disaggregation in IGAULTM.

\begin{tabular}{|c|c|c|}
\hline $\begin{array}{l}\text { IGAULTM } \\
\text { country/region }\end{array}$ & $\begin{array}{l}\text { IGAULTM } \\
\text { acronym }\end{array}$ & Countries included \\
\hline Denmark & DNK & Denmark \\
\hline Germany & DEU & Germany \\
\hline Spain & SPN & Spain \\
\hline France & FRA & France \\
\hline United Kingdom & UK & $\begin{array}{l}\text { United Kingdom of Great Britain } \\
\text { and Northern Ireland }\end{array}$ \\
\hline Netherlands & NLD & Netherlands \\
\hline Russia & RUS & Russia \\
\hline Rest Of Europe & ROE & $\begin{array}{l}\text { Austria, Belgium, Bosnia and Herzegovina, } \\
\text { Bulgaria, Croatia, Czechia, Estonia, Finland, } \\
\text { Greece, Hungary, Ireland, Italy, Latvia, } \\
\text { Lithuania, Norway, Poland, Portugal, Romania, } \\
\text { Serbia, Slovakia, Slovenia, Sweden }\end{array}$ \\
\hline United States & USA & United States of America \\
\hline Canada & CAN & Canada \\
\hline Mexico & MEX & Mexico \\
\hline Brazil & BRA & Brazil \\
\hline Rest Of America & $\mathrm{ROA}$ & $\begin{array}{l}\text { Argentina, Chile, Colombia, Dominican Republic, } \\
\text { Ecuador, French Guyana, Peru, Uruguay, } \\
\text { Venezuela }\end{array}$ \\
\hline $\begin{array}{l}\text { People's } \\
\text { Republic of } \\
\text { China }\end{array}$ & CPR & People's Republic of China \\
\hline Republic of India & IND & Republic of India \\
\hline Japan & JPN & Japan \\
\hline $\begin{array}{l}\text { Republic of } \\
\text { Korea }\end{array}$ & KOR & Republic of Korea \\
\hline Rest Of World & ROW & $\begin{array}{l}\text { Algeria, Australia, Bangladesh, Egypt, } \\
\text { French Polynesia, Indonesia, Jordan, } \\
\text { Kazakhstan, Kuwait, Lebanon, Malaysia, } \\
\text { Morocco, New Zealand, Pakistan, Philippines, } \\
\text { Saudi Arabia, South Africa, Sri Lanka, } \\
\text { Thailand, Tunisia, Turkey, United Arab Emirates, } \\
\text { Viet Nam, Puerto Rico }\end{array}$ \\
\hline
\end{tabular}

$$
\max _{\substack{P \\ q_{r, t, p} \geq 0}} \sum_{\forall t}\left(\pi_{r, t, l p} \cdot q_{r, t, l p}^{P}-\int_{0}^{q_{r, t, l p}^{P}} \mathrm{mc}_{r, t, l p}(s) d s\right),
$$

where $q_{r, t, l p}^{P}$ is the production of the representative producer of livestock product $l p$, in region $r$, in year $t$ and $\mathrm{mc}_{r, t, l p}(s)=$ $\alpha_{r, t, l p}^{P}+\beta_{r, t, l p}^{P} \cdot s$ is the supply curve of the representative producer, when we do not account for the use of antimicrobials in livestock production. Parameters $\alpha_{r, t, l, p}^{P}, \beta_{r, t, l p}^{P}$ are the interval and the slope of the supply curve of each representative producer and $\pi_{r, t, l}$ is the market price in region $r$, or livestock product $l p$, in year $t$. Although the impact of antimicrobials on growth of livestock remains ambiguous (Levy, 2014), antimicrobials are still being 
TABLE 2 | Description of model sets, parameters, variables.

\begin{tabular}{|c|c|}
\hline Element & Description \\
\hline$t$ & Set: model running periods (2015-2028) \\
\hline$r, r r$ & Set: region \\
\hline Ip & Set: type of livestock product (beef, poultry, pork) \\
\hline$f_{r, t, 1 p}^{C}$ & Variable: inverse demand function of region $r$, in year $t$, of product $/ p$ \\
\hline$\pi_{r, t, 1 p}$ & Variable: food market price of region $r$, in year $t$, of product $/ p$ \\
\hline $\mathrm{mc}_{r, t, l p}$ & $\begin{array}{l}\text { Variable: marginal cost of production of region } r \text {, in year } t \text {, of product } \\
\text { ip }\end{array}$ \\
\hline$\mu_{r, t, 1 p}^{A}$ & Variable: dual of constraint (3) of region $r$, in year $t$, of product ip \\
\hline & Variable: consumption of region $r$, in year $t$, of product $/ p$ \\
\hline$q_{r, t, 1 p}^{P}$ & Variable: production of region $r$, in year $t$, of product / $p$ \\
\hline$q_{r r, r, t, l p}^{T}$ & $\begin{array}{l}\text { Variable: livestock transported from region } r \text { to region } r r \text {, in year } t \text {, of } \\
\text { product Ip }\end{array}$ \\
\hline$q_{r, t, 1 p}^{A}$ & $\begin{array}{l}\text { Variable: quantity of antimicrobial use of region } r \text {, in year } t \text {, of } \\
\text { product ip }\end{array}$ \\
\hline$c_{r, r r, t, p}^{T}$ & $\begin{array}{l}\text { Parameter: transportation cost from region } r r \text { to region } r \text {, in year } t \text {, of } \\
\text { product ip }\end{array}$ \\
\hline $\bar{p}_{r, t, / p}^{A}$ & $\begin{array}{l}\text { Parameter: fixed cost index of antimicrobials in region } r \text {, in year } t \text {, of } \\
\text { product Ip }\end{array}$ \\
\hline$\alpha_{r, t, 1 p}^{P}$ & $\begin{array}{l}\text { Parameter: linear term of supply curve of region } r \text {, in year } t \text {, of } \\
\text { product /p }\end{array}$ \\
\hline$\beta_{r, t, 1 p}^{P}$ & $\begin{array}{l}\text { Parameter: quadratic term of supply curve of region } r \text {, in year } t \text {, of } \\
\text { product ip }\end{array}$ \\
\hline$\alpha_{r, t, 1 p}^{C}$ & $\begin{array}{l}\text { Parameter: interval of inverse of inverse demand function of region } r \text {, } \\
\text { in year } t \text {, of product } / p\end{array}$ \\
\hline$\beta_{r, t, 1 p}^{C}$ & $\begin{array}{l}\text { Parameter: slope of inverse of inverse demand function of region } r \text {, } \\
\text { in year } t \text {, of product Ip }\end{array}$ \\
\hline$\alpha_{r, t, 1 p}^{A}$ & $\begin{array}{l}\text { Parameter: value share of antimicrobial use in production of region } r \text {, } \\
\text { in year } t \text {, of product } / p\end{array}$ \\
\hline$\theta_{r, t, 1 p}^{A}$ & $\begin{array}{l}\text { Parameter: impact of antimicrobials to the marginal cost of } \\
\text { production of region } r \text {, in year } t \text {, of product } / p\end{array}$ \\
\hline
\end{tabular}

used in meat production. Following NRC (1999), we assumed that antimicrobials supplement growth, which implies that a decrease in antimicrobial use would increase the marginal cost of production of livestock. In order to model the impact of antimicrobials on livestock production, we introduced the linear term $\theta_{r, t, l p}^{A} \cdot q_{r, t, l p}^{A}$ that is a function of the quantity of antimicrobial used by each producer $\left(q_{r, t, l p}^{A}\right)$. Parameter $\theta_{r, t, l p}^{A}>0$ represented the effect of antimicrobial use on the marginal cost of production of each representative producer. A greater use of antimicrobials decreases the marginal cost of production, i.e.,

$$
\mathrm{mc}_{r, t, l p}\left(q_{r, t, l p}^{P}, q_{r, t, l p}^{A}\right)=\alpha_{r, t, l p}^{P}+\beta^{P} \cdot q^{P}-\theta_{r, t, l p}^{A} \cdot q_{r, t, l p}^{A}
$$

Whenever $\theta_{r, t, l p}^{A}>0$, a smaller quantity of antimicrobials leads to higher marginal cost of production (assuming $q_{r, t, l p}^{A}>0$ ), decreasing production output ceteris paribus. Parameter $\theta_{r, t, l p}^{A}$ is calibrated using data from (NRC, 1999), as explained in the Supplementary Material. In our setting, a smaller value of parameter $\theta_{r, t, l p}^{A}$ implies smaller impact of antimicrobials on livestock growth.
Antimicrobials have a decreasing rate of benefit, meaning that a higher rate of expenditure doesn't necessarily lead to the same rate of growth. We embed this rationale in the representative producer's decision-making by assuming that producers will use a fixed portion of their income $\left(\alpha_{r, t, l p}^{A}\right)$ from sales [right-hand side in (3)] to purchase antimicrobials [left-hand side in (3)] at a price of $\bar{p}_{r, t, l p}^{A}$

$$
\bar{p}_{r, t, l p}^{A} \cdot q_{r, t, l p}^{A}=\alpha_{r, t, l p}^{A} \cdot \pi_{r, t, l p} \cdot q_{r, t, l p}^{P}
$$

When combining (1)-(3), the representative producer's optimization problem becomes

$$
\begin{gathered}
\max _{q_{r, t l p}^{A}, q_{r, t l p}^{P} \geq 0} \sum_{\forall t}\left(\pi_{r, t, l p} \cdot q_{r, t, l p}^{P}-\int_{0}^{q_{r, t l p}^{P}} \mathrm{mc}_{r, t, l p}\left(s, q_{r, t, l p}^{A}\right) d s\right), \\
\text { subject to } \quad q_{r, t, l p}^{A}=\alpha_{r, t, l p}^{A} \cdot \frac{\pi_{r, t, l p}}{\bar{p}_{r, t, l p}^{A}} \cdot q_{r, t, l p}^{P} \perp \mu_{r, t, l p}^{A} .
\end{gathered}
$$

Similarly, each trader of food maximizes their profit, comprising their revenues from selling $q_{r, r, t, l p}^{T}$ to region $r$ (at the regional price $\pi_{r, t, l p}$ ) minus the cost of purchasing an item from region $r r$ (at the regional price $\pi_{r r, t, l p}$ ) and the total cost of transportation $\left(c_{r, r r, t, l p}^{T}\right)$

$$
\max _{\substack{q_{r, r r}^{T}, t, p \\ \in \mathbf{R}_{+}}} \sum_{t}\left(\left(\pi_{r, t, l p}-\pi_{r r, t, l p}-c_{r, r r, t, l p}^{T}\right) q_{r, r r, t, l p}^{T}\right)
$$

Production in each region, as well as imports and exports need to balance with domestic consumption in each region $q_{r, t, l p}^{C}$, i.e.,

$$
q_{r, t, l p}^{C}=q_{r, t, l p}^{P}-\underbrace{\sum_{r r} q_{r r, r, t, l p}^{T}}_{\text {Exports }}+\underbrace{\sum_{r r} q_{r, r r, t, l p}^{T}}_{\text {Imports }}
$$

Finally, the market price in each region is computed via the inverse demand function

$$
\pi_{r, t, l p}=f_{r, t, l p}^{C}\left(q_{r, t, l p}^{C}\right)=\alpha_{r, t, l p}^{C}+\beta_{r, t, l p}^{C} \cdot q_{r, t, l p}^{C},
$$

where $\alpha_{r, t, l p}^{C}, \beta_{r, t, l p}^{C}$ are the interval and the slope, respectively of the inverse demand curve in region $r$, of livestock product $l p$, in year $t$. IGAULTM is used for a comparative analysis for the years 2015-2028. In the business-as-usual scenario, i.e., the "Reference" scenario, no policy is introduced. When a policy is introduced, we are able to observe how quantities and prices change compared to the Reference scenario for the time horizon using a counterfactual analysis. A description of the model's equations along with their derivation are provided in the first section of the Supplementary Material.

Since we focused on trade related to LMICs, we treated trade with the Rest Of World region as exogenous. To ensure model results in the Reference scenario matched historical data 
and projections, we calibrated certain parameters of our model. In a game-theoretic setting, production and trade quantities maximize producers and traders profit, respectively. Therefore, in the calibration process, we ensured that the costs and prices in the individual optimization problems of the agents are such that the reference quantity matched the model output. Based on this principle, we derived the transportation costs $\left(c_{r, r r, t, l p}^{T}\right)$. A detailed description of the calibration process is provided in the third section of the Supplementary Material.

\subsection{Data Sources}

Historical data on livestock production, production prices, and trade were retrieved from the Food and Agriculture Organization (FAO) of the United Nations (U.N.) (FAOSTAT, 2020) for 214 countries. Production, consumption, and trade projections were collected from the Organization for Economic Co-operation and Development (OECD) (OECD-FAO, 2019). Finally, historical and projected regional antimicrobial use data were retrieved from the Center for Disease Dynamics Economics \& Policy (CDDEP, 2020) for 70 countries. In the Reference scenario model output, global production between 2015 (Figure 1) and 2028 increased by 9\%. In the second section of the Supplementary Material we detailed all data sources and calculations for the reference scenario.

\section{SCENARIO DESIGN}

For the purpose of this study, we formulated three scenarios, in accordance with contemporary AMR-related health concerns in LMICs. The design of the scenarios balanced two main objectives. First, we contributed to the ongoing discussion regarding the design of policies against AMR. The scenarios investigated how global coordination policies could curb the use of antimicrobials. Furthermore, the scenarios stressed the importance of the trade network and the interplay between trade and antimicrobial use. We used a global model to assess the impact of the policies on major LMICs, such as India, Brazil, and China. Specifically, we tested a policy targeting antimicrobial use directly; a shock on the trade side where the leading exporter of meat (Brazil) is denied access to the global market; and a shock in global demand where the leading consumer (China) decreases its livestock consumption.

The first scenario assumed that all countries coordinate and implement a user fee on non-human antimicrobial use. Given their commitment, we assume that the policy is enforced on the producers, meaning that purchasing human antimicrobials and using them in animal food ration instead (Graham et al., 2007 ) is prohibited. The idea of a user fee on non-human antimicrobial use in order to reduce antimicrobial use in livestock production has been suggested by Hollis and Ahmad (2013). Our implementation is motivated by Van Boeckel et al. (2017) who studied the impact of a 50\% user fee on antimicrobial use that aimed to curb the use of antimicrobials in the livestock sector by rendering them more expensive. Following Van Boeckel et al. (2017), we examined the impact of a uniform country-level user fee on antimicrobial used in the livestock sector that would gradually increase the price of antimicrobials by $50 \%$ by 2028 . The user fee was assumed to increase the price of antimicrobials by $5 \%$ yearly, starting in 2019.

The second scenario was motivated by the decision of the U.S., in June 2017, to ban imports of beef from Brazil based on concerns regarding the existence of pathogens in imported raw beef and other meat products (USDA, 2017b). In addition, the U.S. currently monitors and re-inspects all meat products imported from Brazil since March 2017 due to safety concerns. Almost $11 \%$ of meat imports from Brazil have not met the standards of USDA's Food Safety and Inspection Service, compared to $\sim 1 \%$ of meat imports from the rest of the world (USDA, 2017a). Similar concerns have been expressed from the EU (EC, 2017), Canada (CFIA, 2020), and China (MALF, 2017). In this scenario, we assessed the case where safety concerns regarding the conditions of meat production in Brazil resulted in Brazil failing to meet international standards, which in turn led all countries to ban imports of meat from Brazil in 2019. Given the importance of exports to Brazil's producers, we assumed that Brazil's meat production will be reformed gradually to address the concerns, similarly to Brazil's commitment in 2017 (USDA, 2017a). For that, we assumed that the ban is relaxed by $11 \%$ yearly compared to reference consumption which leads to Brazil gaining full access to international markets by 2028 .

The third scenario followed the 2016 announcement of meat consumption guidelines by the Government of China that would curtail the growing consumption of meat by $50 \%$ compared to their 2015 consumption by 2030 (NHFPC, 2016). If the goal was to be met starting in 2019, consumption needed to decrease by $5.6 \%$ yearly. For this scenario, we constrained annual consumption of China along the time trajectory [variable $q_{r, t, l p}^{C}$ in Equation (6)]. We applied the same ratio to all three types of meat represented in the model. Livestock consumption in 2028 was decreased by $56 \%$ compared to 2015 and $52 \%$ compared to projected 2028 reference consumption for the scenario inputs.

In summary, the three scenarios were:

- A user fee that increased the price of antimicrobials uniformly by $50 \%$ [parameter $\bar{p}_{r, t, l p}^{A}$ in (4)].

- The first variation assumed a user fee that was adopted by all countries. The fee was introduced in 2019 and increases the price of antimicrobials yearly by $5 \%$.

- Given the disparate effects of the scenario, we studied a variation of the previous scenario, where user fees increased the price of antimicrobials by 5\% each year starting in 2019 . In this variation, the policy was adopted by all countries and regions apart from China.

- A global ban of all meat imports from Brazil due to concerns regarding excessive use of antimicrobials in meat production in 2019, which was relaxed gradually in the following years. Imports from Brazil (variable $q_{r, r r, t, l p}^{T}$, where the exporting region $r r$ is Brazil) were constrained to 0 in 2019 and were relaxed by $11 \%$ yearly 


\section{Reference 2015 Meat Production (Million Metric Tons)}
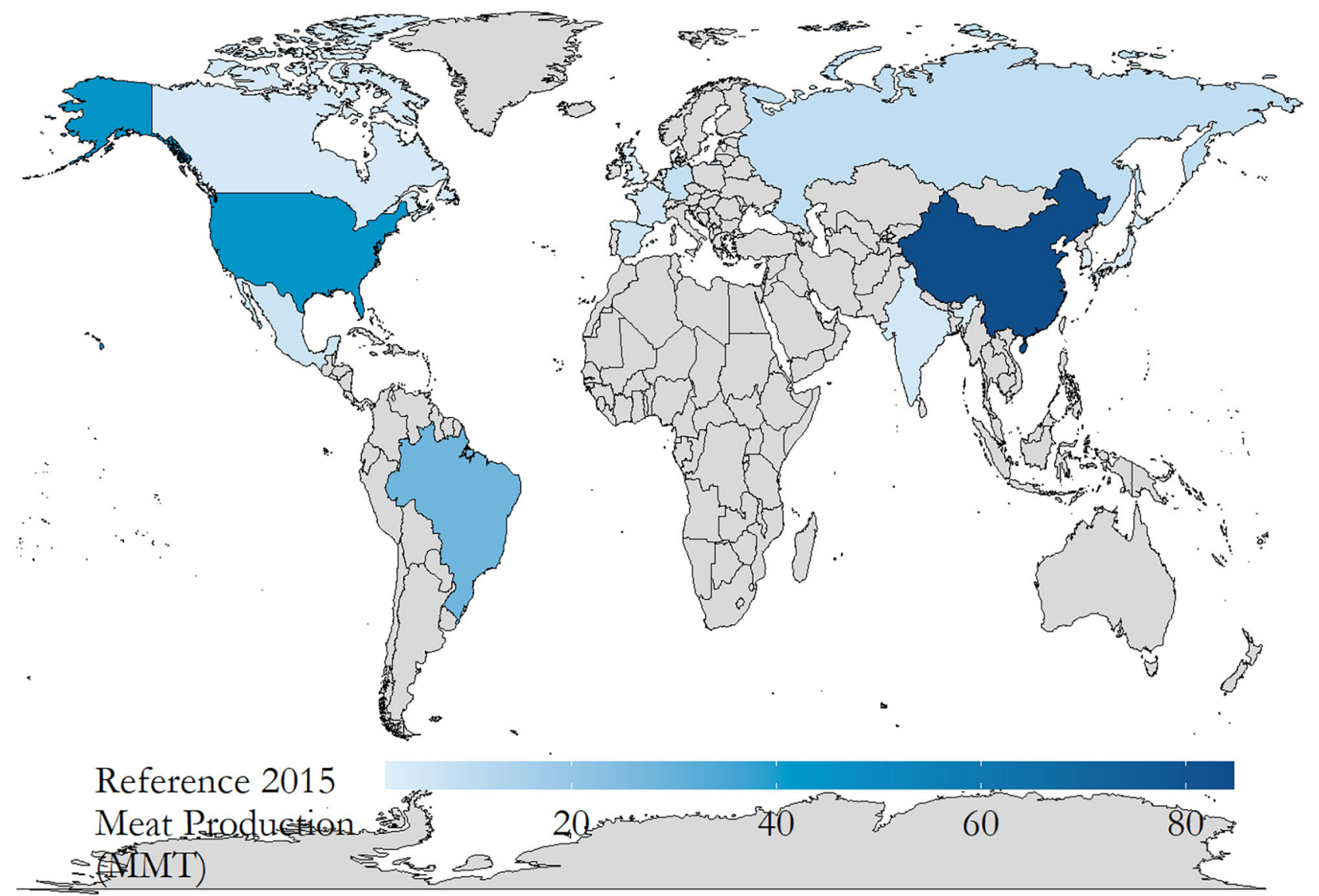

FIGURE 1 | Reference regional livestock production for base year (2015).

compared to reference exports, recovering to reference levels in 2028 .

- A 50\% decrease of reference 2015 demand in China for poultry, pork, and beef by 2028. China's consumption (variable $q_{r, t, l p}^{C}$, where $r$ is China) decreased by $5.6 \%$ each year, starting in 2019 .

\section{RESULTS}

\subsection{Scenario for Global User Fee on Antimicrobials}

The model output showed that a user fee which increased the price of antimicrobials uniformly by $50 \%$ and was adopted by all countries led to a $33 \%$ decrease in global antimicrobial use in 2028 and a negligible decrease in global production. Our results were consistent with Van Boeckel et al. (2017), who found that a $50 \%$ increase of the price of antimicrobials resulted in the U.S. decreasing its antimicrobial use by $31 \%$. The resulting decrease in antimicrobial use in this scenario was fairly uniform, ranging from $31 \%$ (Russia) to $40 \%$ (India). Studying the competition between Canada and the U.S. for European demand revealed the key role that antimicrobial use played in this scenario. Net exports from the U.S. to all European countries were projected to increase by 0.2 Million Metric Tons (MMT), whereas Canada's net exports to Europe were projected to increase by $0.04 \mathrm{MMT}$, mostly to Russia. The fact that the U.S. livestock production sector was less dependent on antimicrobials than Canada's ( 88 $\mathrm{mg} \mid \mathrm{PCU}$ vs. $119 \mathrm{mg} \mid \mathrm{PCU}$ in 2013), implied that the impact of the policy to the cost of production of Canada was higher compared to the U.S., rendering Canada less competitive in the global market ceteris paribus.

The results of the model revealed that the policy increased global trade, since regions traded more, in search of the lowestcost alternative in the new global market equilibrium. The policy 
led to a $17 \%$ increase in global trade in 2028 in the scenario output. China had the highest antimicrobial use in our model in 2013 (CDDEP, 2020). For that, China's meat production was projected to decrease the most, by roughly 2.5 MMT in 2028, which was imported instead, leading to a $55 \%$ increase in imports compared to the reference scenario. On the other hand, countries with many trade partners, namely Brazil, the U.S., and Spain, were projected to increase their net exports compared to the reference scenario regardless of their antimicrobial use. ${ }^{2}$ Given their trade network, the three countries had more potential buyers and thus were better positioned to exploit regional discrepancies. Spanish production increased by $8 \%$, the second greatest increase among all countries in 2028. Moreover, net exports of India increased by $0.7 \mathrm{MMT}$, the highest increase among all countries in 2028. Although India had few trade partners, its production potential and its proximity to China led to a 0.3 MMT increase in net exports to China compared to 2028 reference net exports. Moreover, exports of India to the U.S. also increased by $0.3 \mathrm{MMT}$, which is roughly $55 \%$ of the increase in U.S. total exports in the scenario. The model output suggested that India's low-cost production potential displaced China's meat production, which was heavy in antimicrobial use. Apart from Russia, BRICs (Brazil, Russia, India, China) production and inter-BRICs trade adjusted the most among all regions and regional interconnections in this scenario. Russia's net exports, production, and consumption remained relatively unchanged compared to the reference scenario. Figure 2 shows the change in meat exports of select countries.

The impact of the policy on China, driven by the high antimicrobial use, could prompt China to deviate from the global use fee. Hence, we also studied the case where all countries but China adopt an antimicrobial user fee. In this variation, the model projected that global antimicrobial use was reduced by $12 \%$ in 2028 and global production remained relatively unaffected. We noticed that the simulated impact varies regionally, similarly to the previous scenario. On the one hand, our model results showed that all countries adopting the policy reduced their antimicrobial use by $32 \%$ and faced a $2 \%$ decrease in production. Spain's and Brazil's livestock production were the least affected. India's livestock production increased by $7 \%$ while Spain and Brazil faced a $1 \%$ decrease. On the other hand, China was projected to increase its production by $6 \%$. China's productivity was further enhanced by the $1.4 \%$ increase in antimicrobial use. China in this scenario opted out of introducing the user fee and was able to increase antimicrobial use without becoming less competitive in the global market. As a result, China's exports increased by 1.2 MMT. The model also revealed that the U.S. faced a $14 \%$ decrease in exports in 2028. The result was due to a $70 \%$ decrease in U.S. exports to China and a $37 \%$ decrease in exports to Japan and Korea. China supplied a greater portion of Asian demand in this scenario, forcing competitors, such as the U.S., out of the market. Finally, Japan and the Republic of Korea, who are traditional importers in great proximity to China, were projected to increase their

${ }^{2}$ Brazil: $53 \mathrm{mg} \mid$ PCU, USA: $88 \mathrm{mg} \mid$ PCU, and Spain: $182 \mathrm{mg} \mid \mathrm{PCU}$ in 2013 (CDDEP, 2020). imports by 0.2 and $0.9 \mathrm{MMT}$, respectively. Subsequently, their livestock production decreased by $8 \%$ in 2028 which was the largest decrease among all countries. Figure 3 illustrates how the change in China's exports affect global trade.

\subsection{Global Ban of Imports From Brazil}

The model results showed that the trade ban leads to a rearrangement of trade flows, with the U.S. becoming the largest exporter in 2019, surpassing Brazil in this scenario. The U.S. in this scenario covered $25 \%$ of international demand, previously covered by Brazil. This led to a $12 \%$ increase in U.S. exports in 2019. Although the U.S. had the 6th lowest marginal cost of production among all countries in the reference scenario, it exploited the fact that it retained trade relationships with almost all countries and was projected to supply part of the consumption that was met by imports from Brazil in the reference scenario. Specifically, U.S. exports to Europe, China, and Japan increased by $0.4,0.1$, and $0.1 \mathrm{MMT}$, respectively. That is 47,7 , and $16 \%$ of the curtailed exports of Brazil to the respective countries. The other four countries whose exports benefited the most are India, Canada, Spain, and France, whose exports increased by $4-5 \%$. Figure 4 shows the countries whose exports benefited the most in response to the ban. Brazil's production sector is assumed to gradually adjust in the medium term and is allowed access in the international market. As the restrictions were gradually raised, exports of Brazil recovered gradually as well. Figure 5 shows the change in U.S. and Canada's exports in response to the ban in this scenario.

The model projected that antimicrobial use in 2019 decreased by $6 \%$ in Brazil and increased by $1 \%$ in all other countries, compared to the reference scenario. In the reference scenario, Brazil exported $17 \%$ of its production each year. In this scenario, in 2019, Brazil's producers did not have the option to export and needed to cover only domestic demand. Hence, Brazil's producers could be competitive in the domestic market by producing at a higher marginal cost of production. Consequently, they were able to reduce their antimicrobial use without losing their share in the domestic market in this scenario. On the other hand, the model projected that producers in all other countries increased their production to cover existing demand. In their attempt to be more competitive, they also increased their antimicrobial use in order to increase their productivity. The increase of antimicrobial use for all countries other than Brazil is projected to be between $0.2 \%$ (India) and 2.6\% (Denmark). Figure 6 illustrates how Brazil's projected antimicrobial use gradually increased as the restrictions were lifted. In the medium-term, Brazil's producers in the model increased antimicrobial use to compete in the global market.

Finally, the model estimated that domestic demand of all countries remained unchanged. Revenues of Brazil's livestock producers decreased by $9 \%$ in 2019 and gradually recovered until 2028, whereas all other countries faced a $1 \%$ increase in revenues in 2019.

\subsection{China's Mid-Term Meat Consumption Target}

The model output demonstrated that the severity of the shock, coupled with China's strategic position close to major 


\section{Meat Trade (Million Metric Tons) Global User Fee on Antimicrobials (all), 2028}
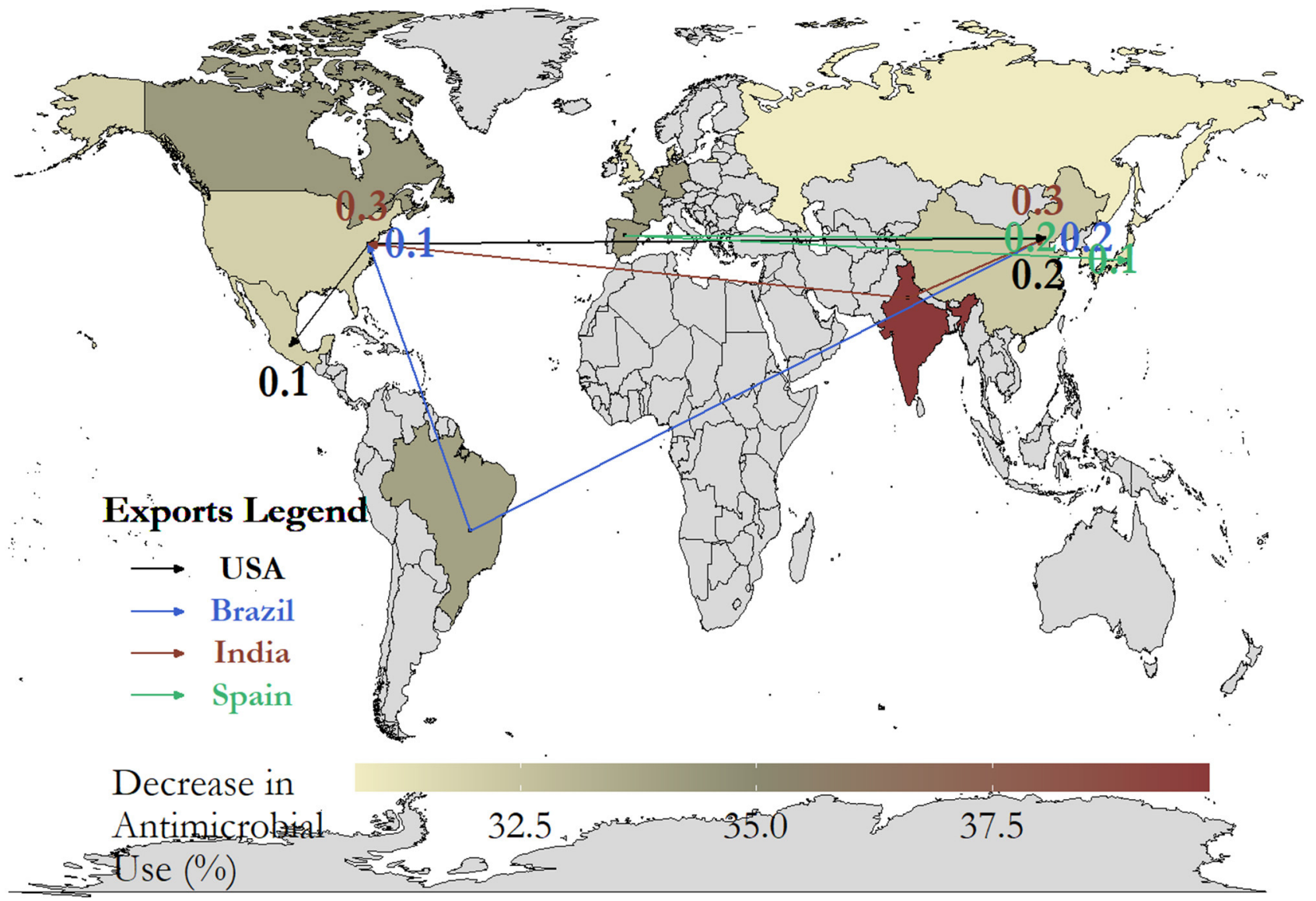

FIGURE 2 | Change in meat exports in million metric tons (MMT). Increasing the cost of antimicrobials reduces antimicrobial use world-wide by $33 \%$. Countries with higher connectivity (Brazil and the US) and countries exporting to major exporters (India) are the ones whose exports benefit the most.

meat importers, resulted in China-the largest net importerturning into the leading net exporter. To better understand this result we need to bear in mind that China was the largest livestock producer globally and that in the reference scenario China's meat production in 2028 was projected to be $9 \%$ larger compared to 2015, based on OECD projections (OECDFAO, 2019). Therefore, given the short- and medium-term production capabilities of China's meat industry, we observed that the curtailment of China's demand resulted in a surplus of supply that can be provided at a lower marginal cost to the international markets, compared to the reference scenario. China's consumption in our model in 2028 became 49 MMT, a $49 \%$ decrease compared to reference 2028 consumption, while China's production in 2028 became 72 MMT, a 23\% decrease compared to reference 2028 production. The difference between projected production and consumption was 23 MMT which amounted to $32 \%$ of China's production in 2028 in this scenario.
Moreover, China's exports in this scenario accounted for $30 \%$ of total exports of all countries. The potential of China's meat industry alone though was not sufficient to describe the changes in this scenario. On the one hand, in the reference scenario China was the largest net importer of meat in 2015 with a total of 3.7 MMT that amounted to $17 \%$ of global imports in our model. The curtailment of China's demand led to a curtailment of imports into China as well. Moreover, China is situated in proximity to Japan and Korea that were major meat importers, while China retained trade relationships with most European markets. From a total of 23 MMT of total net exports in 2028 in this scenario, 92\% was allocated to Europe via Germany and Russia and the rest to Japan and the Republic of Korea.

At a global scale, in 2028, China constituted $30 \%$ of global consumption of meat, covering roughly $5 \%$ of domestic demand via imports in the reference scenario. The model results showed that the curtailment of global demand resulted in more available 


\section{Meat Trade (Million Metric Tons) Global User Fee on Antimicrobials (all but China), 2028}

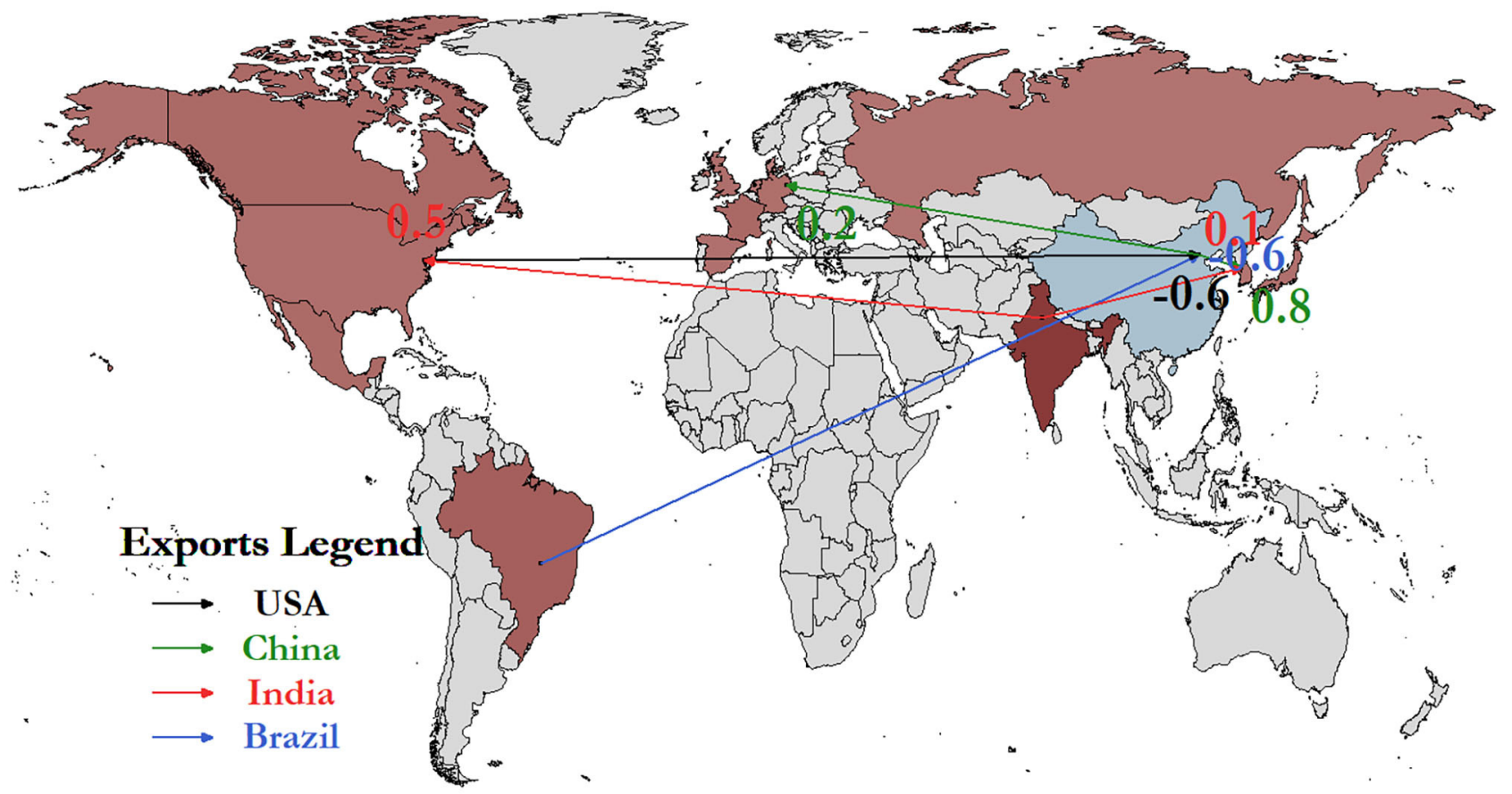

Change in Antimicrobial. Use $(\%)$

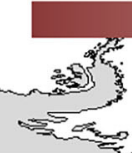

$\checkmark$

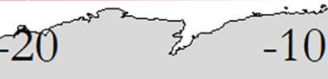

$-10$

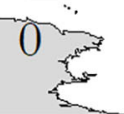

FIGURE 3 | Change in meat exports in million metric tons (MMT). Increased antimicrobial user fees reduce antimicrobial use in livestock production world-wide by $12 \%$. When China does not adopt the policy, it gains a competitive advantage in the global market and its meat exports increase.

low-cost livestock production in China. In this scenario, our model projected that production of the rest of the countries drops by $12 \%$ in 2028 compared to reference 2028 production. Spain experienced a $31 \%$ decrease in production and Brazil experienced an $8 \%$ decrease in production, the largest and smallest decrease among all countries, respectively. Consumption on the other hand was projected to reduce only in China and remained unchanged in most countries. The model output revealed that global income of the livestock sector decreased by $15 \%$ in 2028 and by $7 \%$ intertemporally compared to the reference scenario. Figure 7 shows how the change in China's exports in this scenario affected global livestock trade of LMICs and major exporting countries.

The model results also revealed that global antimicrobial use remained unchanged in this scenario. However, countries facing greater decrease in production increased their antimicrobial use in the scenario output. China's production decreased by $23 \%$ and its antimicrobial use increased by $14 \%$ in 2028 , compared to the reference scenario. Similarly, livestock production in Canada, Germany, and Spain decreased by 20, 25, and 31\%, respectively compared to the reference scenario. The three countries increased their antimicrobial use by 8,10 , and $13 \%$, respectively in order to increase their productivity, which mitigated the impact of the policy on domestic livestock production.

\section{DISCUSSION}

\subsection{Policy Implications}

We assessed the impact of global coordination scenarios on LMICs' livestock production and trade that can lead to more sustainable food animal production. We identified the interplay between country-level antimicrobial use and trade as a key 


\section{Change in Exports \\ (Global Ban of Imports from Brazil)}

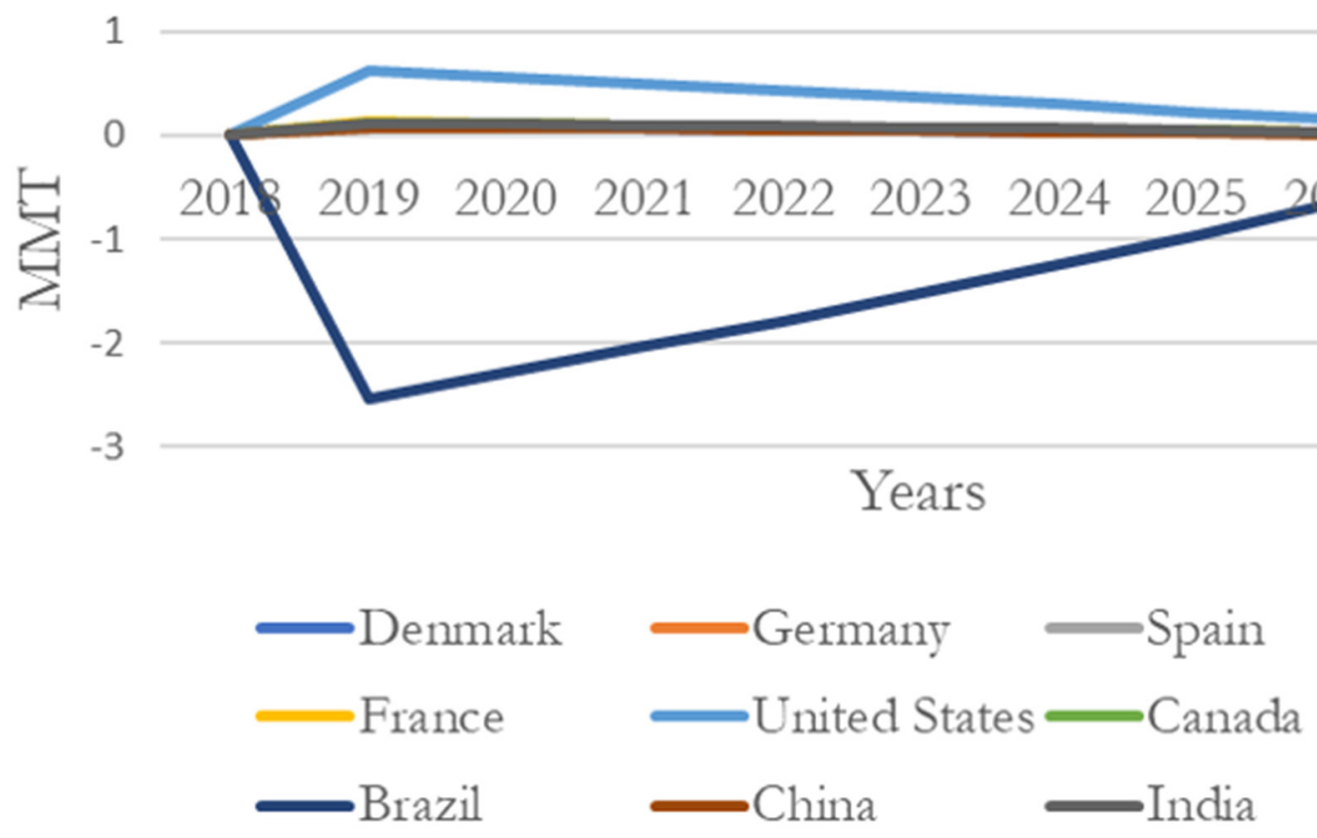

FIGURE 4 | Change in meat exports in million metric tons (MMT) of select countries. The U.S. increases its exports its exports the most in response to the ban of imports from Brazil in 2019. As Brazil is gradually allowed access to international markets, Brazil's exports recover and exports of other major exporters gradually decline.

driver of the change in country-level livestock production. Our model output showed that in all three scenarios, India and Brazil were among the countries whose livestock production either benefited the most or was least impacted, while China's livestock production did not benefit only when it adopted, along with all other countries, an increased antimicrobial user fee.

We observed that the adoption of a user fee on antimicrobials by all countries in our model in the first scenario decreased the use of antimicrobials without significantly impacting global livestock production. However, the impact on LMICs' production may disincentivize them from adopting the global policy in the future. Using our model, we found that deviating from the policy could provide a country with a competitive advantage over the rest. The deviating country was found to increase antimicrobial use of the deviating country. The model output also showed that livestock production of countries with more trade partners was less affected. We suggested that global cooperation could ensure the participation in the policy scheme. This point has both economic and political ramifications. From an economic point of view, a candidate global policy needs to allocate the burden of the policy in a way that does not favor the prospects of one country over another. From a political point of view, policy-makers run the risk of certain countries backing away from an agreement if the proposed policy fails to address the discomfort of certain country-level producers and consumers.

The second scenario illustrated how trade policies related to a trade ban on meat produced in LMICs can affect global antimicrobial use. The model output showed that there were three fundamental reasons why the U.S. assumed the role of leading exporter. The first was the penetration of U.S. production in almost all major consumers. The U.S. retained trade relationships with Europe, China, and Japan that allowed it to benefit from changes in livestock trade. The second was the ability of the U.S. to increase its production and remain competitive compared to the rest of the countries. Finally, India, Canada, Germany, and Spain also saw a significant increase in their exports. The model output suggested that the policy succeeded in decreasing Brazil's antimicrobial use in the short term. However, the ban created more space for competition among all other countries who increased their antimicrobial use in an effort to increase their productivity and cover a greater portion of global demand in the model scenario.

The third scenario underlined the potential of China's meat sector to transform from a major importer to the leading exporter, assuming a decrease in China's meat consumption. We concluded that this result is possible given the established trade 


\section{Meat Trade (Million Metric Tons) Global Ban of Imports from Brazil, 2019}
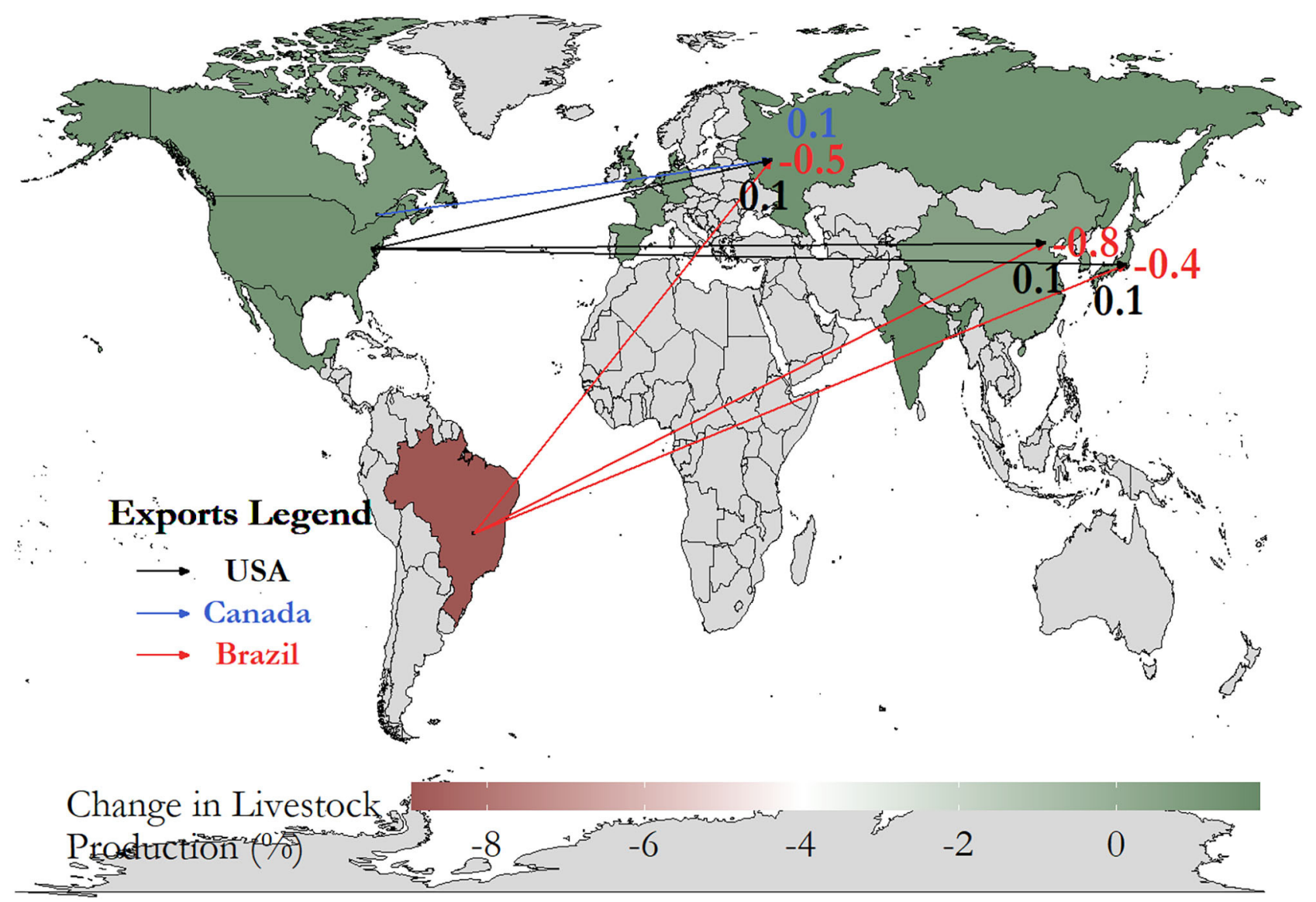

FIGURE 5 | Change in meat exports in million metric tons (MMT). The ban decreases Brazil's production by 8.5\% in 2019. The U.S. assumes the role of leading exporter, by increasing its exports to all trade partners, including China, Europe, and Japan.

relationships of China with major importers, such as Japan and Europe. Moreover, we were able to isolate the interconnections with the highest potential for China. Finally, this scenario highlighted how changes in China's meat consumption can severely affect, via trade, global production, resulting in losses for producers worldwide. China's livestock producers in our model increased antimicrobial use in the livestock sector in this scenario in order to increase their productivity and cover a larger portion of the international market.

\subsection{Limitations}

The limitations of our analysis arose from the unavailability of sub-national production, consumption, and trade data for all countries and the uncertainty regarding the impact of antimicrobial use on livestock growth. IGAULTM was designed to account for the impact of antimicrobials on livestock production (parameter $\theta_{r, t, l p}^{A}$ ). However, there is evidence that antimicrobials may not contribute to growth promotion (Levy, 2014), or increase profitability (Graham et al., 2007). In this study, following NRC (1999), we assumed that antimicrobials had a positive impact on breeding productivity. Finally, countrylevel antimicrobial expenditures by livestock producers were not available and were computed using data from NRC (1999). These are critical parameters in our analysis. Hence, the provided quantitative results served to illustrate the underlying economic rationale behind antimicrobial use in the global livestock market and were conditional on available data at the time this work was conducted.

The antimicrobial use of each country was inferred using data from CDDEP (2020) which did not distinguish between antimicrobials for therapeutic and non-therapeutic purposes. To the best of our knowledge, the purpose of antimicrobial use at the country level is not publicly available, which impacted scenario design and implementation. With such data, we would have 


\section{Change in Antimicrobial Use (Global Ban of Imports from Brazil)}
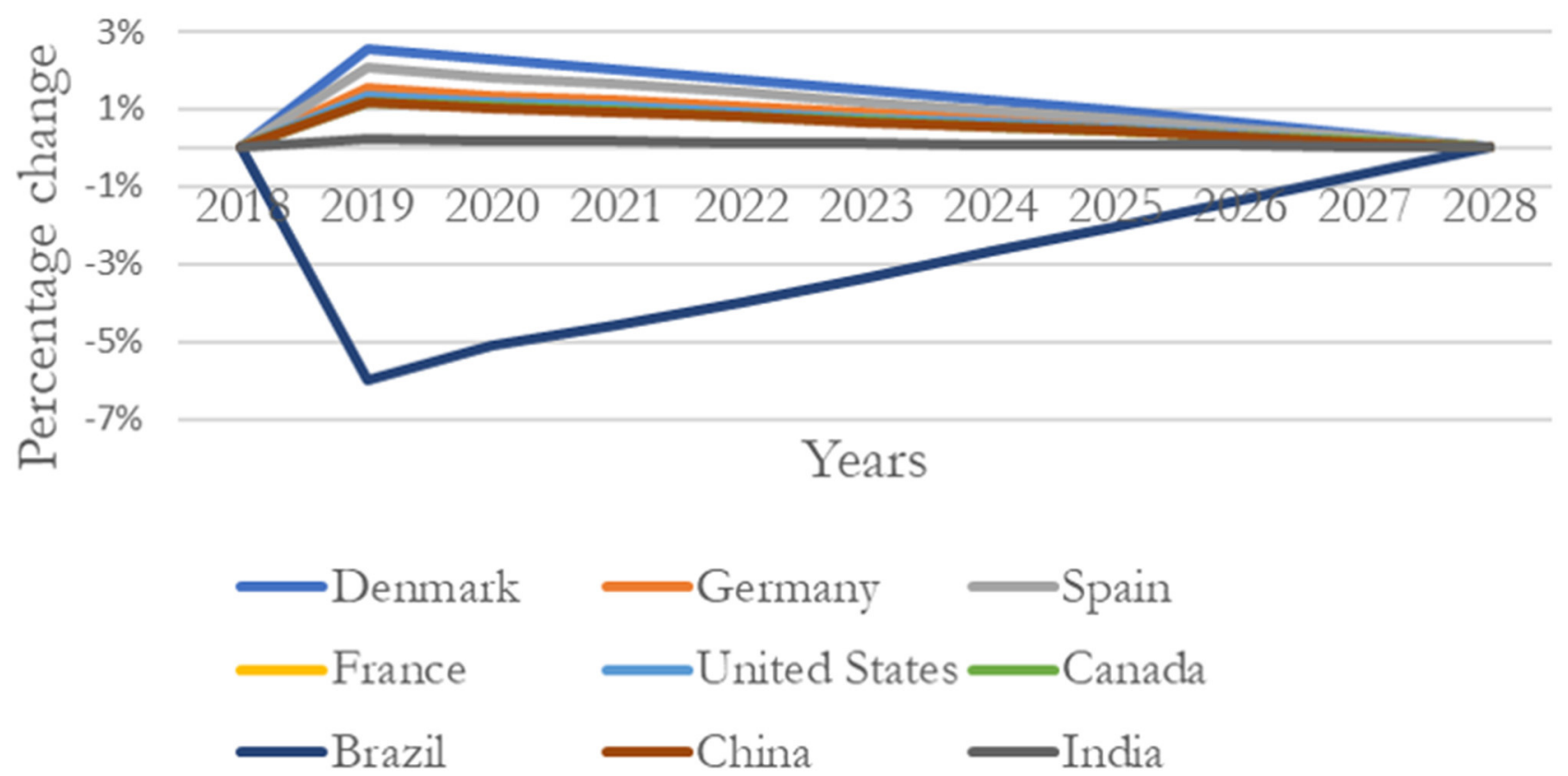

FIGURE 6 | Percentage change in antimicrobial use compared to reference antimicrobial use. The ban leads to a decrease in antimicrobial use in Brazil's livestock production sector and an increase of antimicrobial use in the livestock production sectors of the other countries in 2019. Brazil's livestock producers seek to increase their productivity by increasing antimicrobial use when allowed access to the international market.

been able to formulate more informed scenarios that targeted growth-promoting antimicrobial use. In the case where only growth-promoting antimicrobials were either banned or taxed, the producers' decision-making process would need to account for purchase and use of human antimicrobials instead. Moreover, antimicrobials for therapeutic purposes in some cases reflect poor sanitary breeding conditions. Our model did not account for the substitution between sanitary conditions and antimicrobial use in every country, since such data were not available.

As described in the Methods section, historical data on production, consumption, and trade were retrieved from FAOSTAT. The FAOSTAT dataset comprised consistent data up to 2015 and reference production, trade, and consumption projections were computed by applying the growth rates of OECD data to the respective quantities. In some cases OECD's outlook did not report the growth rate of a particular country, but of a region. In that case we used the growth rate of the next largest region to project country-level production, consumption, and trade to 2028. Modeling of the supply side was driven by the available data and the question at hand, which required us to represent a range of countries at the global level. We distinguished between three types of livestock, namely beef, pork, and poultry. We did not explicitly model endogenous investment decisions. This simplification was based on the time horizon of our analysis, which was short- and medium-term, and the unavailability of livestock farm capacity data at the level of regional detail required in this study. Finally, demand elasticity estimates were collected from various sources and were not available at the country level for most countries. When countrylevel demand elasticities were not available, the regional demand elasticity is applied to the countries of each region. Therefore, our analysis may fail to grasp the variance in demand patterns of countries in the same region. We provided a detailed list of data sources in the Supplementary Material.

\section{CONCLUSIONS}

The use of antimicrobials in the livestock sector is based on the assumption that antimicrobials enhance livestock growth. Even when veterinary medicinal products are regulated, countries may not have the resources to enforce the regulations. In resourcelimited LMICs, taxing or banning antimicrobial use in livestock production could result in producers purchasing antimicrobials from other providers (Barroga et al., 2020). Consequently, enhanced AMR monitoring systems and surveillance of antimicrobials consumption (Cheng et al., 2014) are necessary complements to global policies against AMR. 


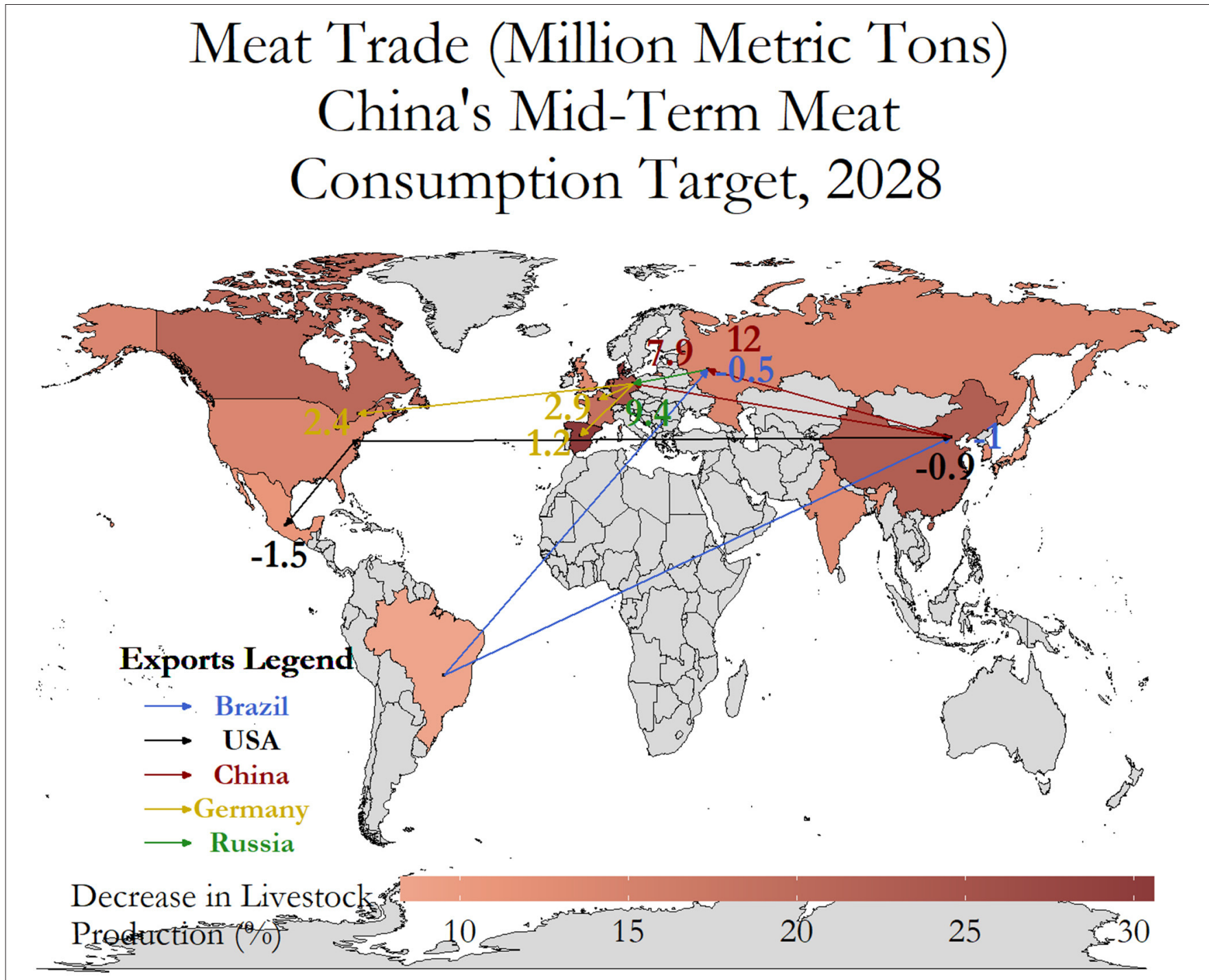

FIGURE 7 | Change in meat exports in million metric tons (MMT). Curtailment of China's demand results in China having a surplus of low-cost meat that is sold in the global market. China becomes the leading exporter by increasing its exports to all countries via Germany and Russia.

Moreover, there is evidence in the case of poultry in Denmark that the savings from restricting antimicrobial use in livestock production almost completely offset the losses in animal growth (WHO, 2002). Hence, future research needs to quantify under what conditions it is economically beneficial for livestock producers to use antimicrobials. Under certain conditions, the boost in livestock productivity may not justify the purchase of antimicrobials. Identifying these conditions can inform animal breeding practices and future AMR policy design.

AMR limits the therapeutic and prophylactic effects of existing antimicrobials on humans and animals (Collignon et al., 2016). For that, even when it is economically beneficial for livestock producers to use antimicrobials, the WHO suggests that countries restrict the use of antimicrobials which are "critically important" for human medicine in the livestock sector.
In this paper we showed that LMICs' livestock production can be affected by policies against AMR. The disparity of the impact between countries in our scenarios suggest the need for more detailed data on antimicrobial use and regional production costs. Specifically, there is a need for more data on the use of different classes of antimicrobials, the purpose of the use of each antimicrobial, and the contribution of each to livestock producers' profitability. Incorporating the different uses of different classes of antimicrobials into the producers' decision-making problem would allow us to study scenarios that target only the particular subset of growthpromoting antimicrobials.

From a societal perspective, limiting AMR can reduce secondline treatment and hospitalization costs. Moreover, addressing AMR by restricting the use of antimicrobials in food animal production contributes toward meeting Goal 3 of the United 
Nation's Sustainable Development Goals that emphasizes health and well-being. To the extent that restricting antimicrobials in food animal production contributes to sustainable agricultural production, tackling AMR contributes also to Goals 2 and 12 of the United Nation's Sustainable Development Goals (IACG, 2018). In this study we emphasized the interplay between the underlying economic incentive of antimicrobial use and livestock trade as key aspects in the design of global policies. Our framework allowed us to represent the decision-making process of different agents in global livestock supply chains. In the case of a tax on antimicrobial use in livestock production, the framework can be enhanced to represent country-level or international agencies that decide the optimal tax on antimicrobial use in livestock production by taking into account also the healthcare costs associated with AMR. This kind of analysis would require robust, countrylevel estimates of all direct and indirect costs related to AMR. Given the complexity of AMR, which spans more dimensions than the ones emphasized in this study, informed policy design calls for more data on livestock production and antimicrobial use.

\section{DATA AVAILABILITY STATEMENT}

The original contributions presented in the study are included in the article/Supplementary Material, further inquiries can be directed to the corresponding author/s.

\section{REFERENCES}

Barroga, T., Morales, R., Benigno, C., Castro, S., Caniban, M., Cabullo, M., et al. (2020). Antimicrobials used in backyard and commercial poultry and swine farms in the Philippines: a qualitative pilot study. Front. Vet. Sci. 7:329. doi: $10.3389 /$ fvets.2020.00329

CDC (2013). Antibiotic Resistance Threats in the United States, 2013. Atlanta, GA: Technical report, Centers for Disease Control and Prevention. U.S. Department of Health and Human Services.

CDDEP (2020). The Center for Disease Dynamics Economics \& Policy. ResistanceMap: Antibiotic Resistance. 2017. Available online at: https:// resistancemap.cddep.org/CountryPageSub.php?country=United_States (accessed June 11, 2020).

CFIA (2020). Final Report of an Audit of the Meat Inspection Systems and Animal Health Controls of Brazil-October 15 to 26, 2018. Technical report, Canadian Food Inspection Agency.

Cheng, G., Hao, H., Xie, S., Wang, X., Dai, M., Huang, L., et al. (2014). Antibiotic alternatives: the substitution of antibiotics in animal husbandry? Front. Microbiol. 5:217. doi: 10.3389/fmicb.2014.00217

Collignon, P., Conly, J., Dang Ninh, T., Donado-Godoy, P., Fedorka-Cray, P., Fernandez, H., et al. (2016). World Health Organization ranking of antimicrobials according to their importance in human medicine: a critical step for developing risk management strategies to control antimicrobial resistance from food animal production. Clin. Infect. Dis. 63, 1087-1093. doi: $10.1093 / \mathrm{cid} / \mathrm{ciw} 475$

EC (2017). Final Report of an Audit Carried out in Brazil From 02 May 2017 to 12 May 2017 in Order to Evaluate the Operation of Controls Over the Production of Beef, Horse and Poultry Meat, and Products Derived Therefrom Intended for Export to the European Union. Technical report, European Commission.

ECOSOC (2015). Transforming Our World: The 2030 Agenda for Sustainable Development. Technical report, United Nations Economic and Social Council. United Nations.

\section{AUTHOR CONTRIBUTIONS}

CA, ASL, and SS designed the scenarios and drafted the manuscript. CA and ASL collected all data used in model calibration and scenario implementation, and performed the analysis of the results. CA and WJ coded the model in GAMS and CA implemented the scenarios in GAMS. SS supervised all research activities related to this project. All authors contributed to the article and approved the submitted version.

\section{FUNDING}

CA, WJ, and SS were funded through Johns Hopkins University discretionary accounts. Research support for CA and SS was funded in part by NSF Grant \#1745375 (EAGER: SSDIM: Generating Synthetic Data on Interdependent Food, Energy, and Transportation Networks via Stochastic, Bi-level Optimization). Support for AL was provided by the Johns Hopkins Center for a Livable Future-Lerner Fellowship. The funders had no role in model design, analysis, decision to publish, or preparation of the manuscript.

\section{SUPPLEMENTARY MATERIAL}

The Supplementary Material for this article can be found online at: https://www.frontiersin.org/articles/10.3389/fsufs. 2021.650315/full\#supplementary-material

ECOSOC (2019). Special Edition: Progress Towards the Sustainable Development Goals. Report of the Secretary-General. Technical report, United Nations Economic and Social Council. United Nations.

FAOSTAT (2020). Food and Agriculture Organization Statistical Database. United Nations. Retrieved from: http://www.fao.org/faostat/en/ (accessed June 11, 2020).

George, A. (2018). Antimicrobial resistance, trade, food safety and security. One Health 5, 6-8. doi: 10.1016/j.onehlt.2017.11.004

Graham, J. P., Boland, J. J., and Silbergeld, E. (2007). Growth promoting antibiotics in food animal production: an economic analysis. Public Health Rep. 122, 79-87. doi: 10.1177/003335490712200111

Hanefeld, J., Khan, M., Tomson, G., and Smith, R. (2017). Trade is central to achieving the sustainable development goals: a case study of antimicrobial resistance. Br. Med. J. 358. doi: 10.1136/bmj.j3505

Hollis, A., and Ahmad, Z. (2013). Preserving antibiotics, rationally. N. Engl. J. Med. 369, 2474-2476. doi: 10.1056/NEJMp1311479

IACG (2018). AMR Indicators and Their Relevance to the Global Indicator Framework for the SDGs and Targets for the 2030 Agenda for Sustainable Development. Technical report, Analytic support provided by McKinsey \& Company, funded by the Wellcome Trust, to inform the United Nations Inter-Agency Coordination Group (IACG) on Antimicrobial Resistance.

Landers, T. F., Cohen, B., Wittum, Thomas, E., and Larson, E. L. (2012). A review of antibiotic use in food animals: perspective, policy, and potential. Public Health Rep. 127, 4-22. doi: 10.1177/003335491212700103

Levy, S. (2014). Reduced antibiotic use in livestock: how Denmark tackled resistance. Environ. Health Perspect. 122, A160-A165. doi: $10.1289 /$ ehp.122-A160

MALF (2017). Statement by the Brazilian Ministry of Agriculture, Livestock and Food Supply. Brasília: Ministry of Agriculture, Livestock and Food Supply of Brazil. Available online at: http://www.brazil.gov.br/about-brazil/news/2017/ 03/china-announces-full-reopening-of-its-market-to-brazilian-meat 
Martin, M. J., Thottathil, S. E., and Newman, T. B. (2015). Antibiotics overuse in animal agriculture: a call to action for health care providers. Am. J. Public Health 105, 2409-2410. doi: 10.2105/AJPH.2015.302870

NHFPC (2016). Statement: Regarding the Official Version of "The Pagoda of Balanced Diet for Chinese Residents (2016)". Beijing: National Health and Family Planning Commission of China. Available online at: http://dg.cnsoc. org/article/04/8a2389fd54b964c80154c1d781d90197.html

NRC (1999). The Use of Drugs in Food Animals: Benefits and Risks. Washington, DC: The National Academies Press.

OECD-FAO (2015). Aglink-Cosimo Model Documentation. A Partial Equilibrium Model of World Agricultural Markets. Paris: Organisation for Economic Cooperation and Development and Food and Agriculture Organization of the United Nations (OECD-FAO).

OECD-FAO (2019). OECD-FAO Agricultural Outlook 2019-2028. Organisation for Economic Co-operation and Development and Food and Agriculture Organization of the United Nations. Retrieved from: http://www.fao.org/ faostat/en/ (accessed June 11, 2020).

O'Neill, J. (2014). Antimicrobial Resistance: Tackling a Crisis for the Health and Wealth of Nations. Technical report, The UK Prime Minister commissioned the Review on Antimicrobial Resistance to address the growing global problem of drug-resistant infections. It is Chaired by Jim O'Neill and supported by the Wellcome Trust and the UK Government, but operates and speaks with full independence from both.

Rogers Van Katwyk, S., Danik, M., Pantis, I., Smith, R., Røttingen, J.A., and Hoffman, S. J. (2016). Developing an approach to assessing the political feasibility of global collective action and an international agreement on antimicrobial resistance. Global Health Res. Policy 1:20. doi: 10.1186/s41256-016-0020-9

Tilman, D., Balzer, C., Hill, J., and Befort, B. L. (2011). Global food demand and the sustainable intensification of agriculture. Proc. Natl. Acad. Sci. U.S.A. 108, 20260-20264. doi: 10.1073/pnas.1116437108

USDA (2017a). Perdue: USDA Halting Import of Fresh Brazilian Beef. Washington, DC: U.S. Department of Agriculture. Available online at: https://www.usda. gov/media/press-releases/2017/06/22/perdue-usda-halting-import-freshbrazilian-beef (accessed June 22, 2017).

USDA (2017b). USDA on Tainted Brazilian Meat: None Has Entered U.S., 100 Percent Re-Inspection Instituted. Washington, DC: U.S. Department of
Agriculture. Available online at: https://www.usda.gov/media/press-releases/ 2017/03/22/usda-tainted-brazilian-meat-none-has-entered-us-100-percentre (accessed March 22, 2017).

Van Boeckel, T. P., Brower, C., Gilbert, M., Grenfell, B. T., Levin, S. A., Robinson, T. P., et al. (2015). Global trends in antimicrobial use in food animals. Proc. Natl. Acad. Sci. U.S.A. 112, 5649-5654. doi: 10.1073/pnas.1503141112

Van Boeckel, T. P., Glennon, E. E., Chen, D., Gilbert, M., Robinson, T. P., Grenfell, B. T., et al. (2017). Reducing antimicrobial use in food animals. Science 357, 1350-1352. doi: 10.1126/science.aao1495

Van Boeckel, T. P., Pires, J., Silvester, R., Zhao, C., Song, J., Criscuolo, N. G., et al. (2019). Global trends in antimicrobial resistance in animals in low- and middle-income countries. Science 365:eaaw1944. doi: 10.1126/science.aaw1944

Wegener, H. C., Aarestrup, F., Jensen, L., Hammerum, A., and Bager, F. (1999). Use of antimicrobial growth promoters in food animals and Enterococcus faecium resistance to therapeutic antimicrobial drugs in Europe. Emerg. Infect. Dis. 5, 329-335. doi: 10.3201/eid0503.990303

WHO (2002). Impacts of Antimicrobial Growth Promoter Termination in Denmark. Technical report, World Health Organization.

WHO (2011). Critically Important Antimicrobials for Human Medicine, 3rd Revision. Technical report, World Health Organization.

WHO (2015). Global Action Plan on Antimicrobial Resistance. Technical report, World Health Organization.

Woolhouse, M., Ward, M., van Bunnik, B., and Farrar, J. (2015). Antimicrobial resistance in humans, livestock and the wider environment. Philos. Trans. $R$. Soc. B 370:20140083. doi: 10.1098/rstb.2014.0083

Conflict of Interest: The authors declare that the research was conducted in the absence of any commercial or financial relationships that could be construed as a potential conflict of interest.

Copyright (c) 2021 Avraam, Lambrou, Jiang and Siddiqui. This is an open-access article distributed under the terms of the Creative Commons Attribution License (CC $B Y)$. The use, distribution or reproduction in other forums is permitted, provided the original author(s) and the copyright owner(s) are credited and that the original publication in this journal is cited, in accordance with accepted academic practice. No use, distribution or reproduction is permitted which does not comply with these terms. 